\title{
The hormonal response to stress is not modified by the dramatic decrease in prolactin plasma concentration during surgery for microprolactinoma
}

R Guieu, H Dufour, C Devaux, T Brue, J P Rosso, F Grisoli, M Grino, A Enjalbert, D Begoud, N Broder, $H$ Rochat, P Jaquet

\begin{abstract}
Objectiives-To determine the endocrine response to surgical stress in a homogeneous population of 36 women with microprolactinomas, particularly to evaluate the effect of the sharp decrease in plasma prolactin on stress induced hormonal secretion. In addition, the effects of exogenous opiates on prolactin secretion were studied. Methods-The plasma kinetics of cortisol, prolactin, ACTH, GH, and $\beta$-endorphin like immunoreactivity ( $\beta$-ELI) were analysed by including patients operated on with strict anaesthetic and surgical protocols, and by sampling blood every $10 \mathrm{~min}$ utes, starting at premedication up to 3 hours after induction.

Results and conclusions-(a) Surgical stress or opiate administration did not induce prolactin release in patients with microprolactinoma. (b) The dramatic decrease in prolactin concentrations have apparently no effect on the release of other hormones involved in stress. (c) The existence of an early GH peak, independently of any surgical procedure, strongly suggests that $\mathbf{G H}$ is released by surgical stress whereas $\beta$-endorphin is secreted in response to pain. Thus GH may be a useful marker of surgical stress.

(f Neurol Neurosurg Psychiatry 1998;65:502-507)
\end{abstract}

Keywords: anaesthesia; microprolactinomas; surgical stress; endorphins

N Broder

D Begoud

Labortatoire de Biochimie

J P Rosso

Service

d'Endocrinologie, Hopital Nord

Bd P Dramard 13015, Marseille, France

M Grino

Correspondence to: Dr R Guieu, Laboratoire de Biochimie, Faculté de Médecine Secteur Nord, UMR CNRS 6560, Institut Fédératif J Roche,

Bd P Dramard 13015,

Marseille, France. Fax 0033 0491657595 .

Received 14 October 1997 and in revised form 1 December 1997

Accepted 4 December 1997

: (1) to study the hormonal respo in particular that of the anterior pituitary, and surgical stress in a population highly homogeneous in terms of sex and pathology (women with microprolactinomas) and anaesthesia protocol; (2) to evaluate the immediate effect of the decrease in prolactin concentrations on the concentration of other hormones involved in the stress response such as cortisol, ACTH, GH, and $\beta$-endorphin, by taking frequent samples before, during, and after surgery. Although it has been established that endogenous opioids, in particular $\beta$-endorphin, stimulate prolactin secretion, ${ }^{13}$ little is known about the effect of prolactin on $\beta$-endorphin secretion in humans; (3) because of previous reports that opiates can induce the release of both glycosylated and nonglycosylated prolactin forms by non-adenoma cells ${ }^{14}$ we also investigated the in vivo action of exogenous opiates on prolactin secretion by adenoma cells in these patients.

\section{Patients and methods}

Thirty six women between 18 and 44 (mean 29) years of age with a microprolactinoma, as well as 10 healthy women (without endocrine abnormalities and without treatment) between 21 and 39 (mean 31) years of age were included in the study. The diagnostic criteria for microprolactinoma were: (1) a syndrome of amenorrhoea or amenorrhoea-galactorrhoea; (2) a pituitary tumour seen on MRI and not larger than $10 \mathrm{~mm}$ at its largest diameter; and (3) basal PRL concentrations higher than 20 $\mu \mathrm{g} / 1$ and not exceeding $250 \mu \mathrm{g} / \mathrm{l}$, not stimulated by TRH or metoclopramide. All patients and controls were informed of the aims and methods of the study according to the Helsinki convention and we obtained the agreement of the ethics committee of Timone Teaching Hospital. Exclusion criteria were patients with a mixed adenoma, those with chronic pain, and those presenting a contraindication to anaesthesia or surgery. Those with a previous transphenoidal resection for prolactin secreting adenoma were also excluded. Among the 36, 12 had been taking bromocriptine (2.5 to 5 $\mathrm{mg} / \mathrm{kg}$ ) for 1 to 60 (mean 17) months before surgery. Treatments were stopped 1 to 10 months before the surgery. Twenty four were operated on without a delay.

SURGERY

All the patients were operated on by the same surgeon, via the rhinoseptal route. The operation began at $830 \mathrm{am} \pm 5$ minutes, and duration as measured between the skin incision and the end of resection was $50 \pm 5$ minutes.
ANAESTHESIA

Anaesthesia was performed by the same anaesthetist. Premedication was given 30 minutes before induction and comprised $10 \mathrm{mg} / \mathrm{kg}$ morniflumate (suppository) and $20 \mu \mathrm{g} / \mathrm{kg}$ lorazepam (intramuscular). Induction was with 
Table 1 Means (SD) of basal concentrations of pituitary hormones and of cortisol measured in 36 patients with microprolactinomas and in 10 healthy women (in patients, samples were collected before premedication, in controls, samples were drawn between 800 and $830 \mathrm{am}$ )

\begin{tabular}{llll}
\hline Hormone & $\begin{array}{l}\text { Patients } \\
(n=36)\end{array}$ & $\begin{array}{l}\text { Controls } \\
(n=10)\end{array}$ & $\begin{array}{l}\text { Mann-Whitney } \\
\text { test }\end{array}$ \\
\hline ACTH $(\mathrm{pg} / \mathrm{ml})$ & $17 / 9$ & $20 / 11$ & $\mathrm{p}>0.05$ \\
Cortisol $(\mu \mathrm{g} / 100 \mathrm{ml})$ & $16.7 / 4.7$ & $15.3 / 3.5$ & $\mathrm{p}>0.05$ \\
$\begin{array}{l}\beta \text {-Endorphin-like } \\
\text { immunoreactivity }(\mathrm{pg} / \mathrm{ml})\end{array}$ & $22 / 5.9$ & $22.6 / 7$ & $\mathrm{p}>0.05$ \\
GH $(\mu \mathrm{g} / \mathrm{l})$ & $3.8 / 0.47$ & $3.2 / 0.6$ & $\mathrm{p}>0.05$ \\
Prolactin $(\mu \mathrm{g} / \mathrm{l})$ & $93 / 44$ & $8 / 1.5$ & $\mathrm{p}<0.0001$ \\
\hline
\end{tabular}

Except for prolactin, there is no significant difference in basal concentrations of stress hormones between patients and controls. propofol $(2.5 \mathrm{mg} / \mathrm{kg})$ and pancuronium bromide $(8 \mathrm{mg} / \mathrm{kg})$. After intubation, analgesia was obtained with $20 \mu \mathrm{g} / \mathrm{kg}$ phenoperidine and maintained with $\mathrm{N}_{2} \mathrm{O} / \mathrm{O}_{2}(60 \% / 40 \%)$. When the transpalatine retractors were installed, 20 $\mu \mathrm{g} / \mathrm{kg}$ alfentanil was given.

SAMPLES

A total of 23 samples (each of $3 \mathrm{ml}$ ) of venous blood were drawn into EDTA from each patient, using a small catheter. The first sample
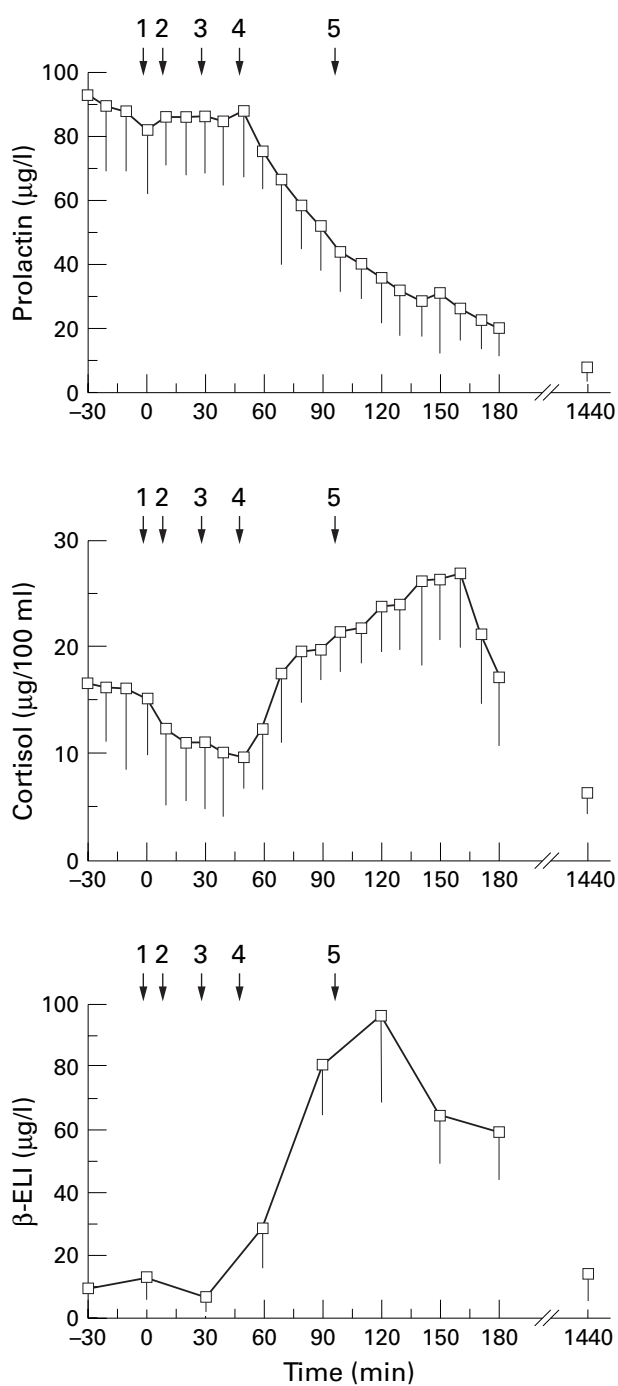

was taken before premedication (30 minutes before induction), then every 10 minutes, starting 20 minutes before anaesthetia induction up to 80 minutes after extubation. A final sample was taken 24 hours after extubation. In controls, only one sample was taken, between 800 and $830 \mathrm{am}$. Samples were immediately centrifuged at $2500 \mathrm{~g}$ for 10 minutes and supernatant liquids were frozen at $-80^{\circ} \mathrm{C}$ before analysis.

\section{ASSAY METHODS}

Prolactin was assayed by immunoenzymofluorescence with a Stratus II apparatus (DADE®). Sensitivity was $0.4 \mathrm{ng} / \mathrm{ml}$ and the intra-assay coefficient of variation was $4 \%$. Cortisol and GH were assayed by chemiluminescence using an Immulite ${ }^{\circledR}$ (Behring) instrument. Sensitivity and intra-assay coefficient of variation were $4 \mathrm{pg} / \mathrm{ml}$ and $6 \%$ for $\mathrm{GH}$, and 2 $\mathrm{ng} / \mathrm{ml}$ and $9 \%$ for cortisol. ACTH and $\beta$-endorphin-like immunoreactivity (referred to as $\beta$-endorphin in the rest of the paper) were assayed by radioimmunoassay as previously

Figure 1 Means (SD) of preoperative, perioperative, and postoperative concentrations of some hormones involved in the response to stress during rhinopalatine route resection of microprolactinomas in 32 women. Samples were taken every 10 minutes starting just before premedication (30 minutes before induction) and up to 80 minutes after extubation. Time 1 is induction, time 2 skin incision, time 3 the installation of transpalatine retractors, time 4 the end of adenoma resection, and time 5 extubation. Note that between time 1 and 2 phenoperidine $(20 \mu \mathrm{g} / \mathrm{kg})$ and at time 3, alfentanyl $(20 \mu \mathrm{g} / \mathrm{kg})$ were administered. 


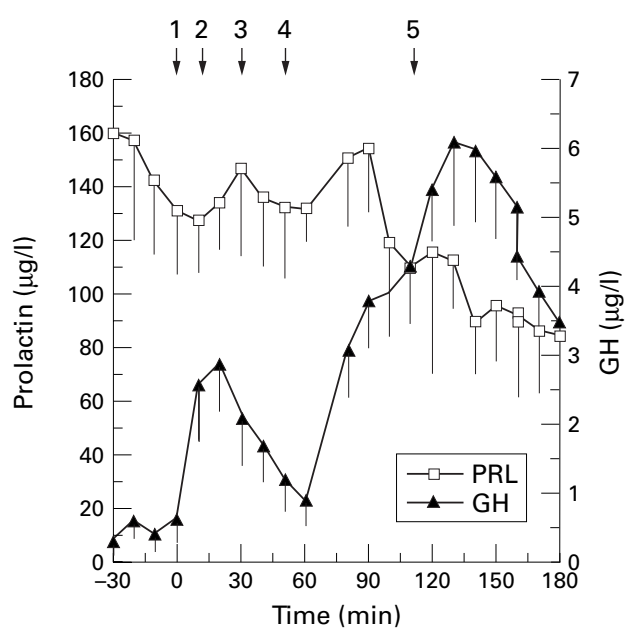

Figure 2 Means (SD) of preoperative, perioperative, and postoperative concentrations of $G H$ and prolactin during surgical resection of microprolactinomas in three women in whom the operation was not successful. Samples were taken as in fig 1. Note the absence of a rapid drop after the end of the resection.
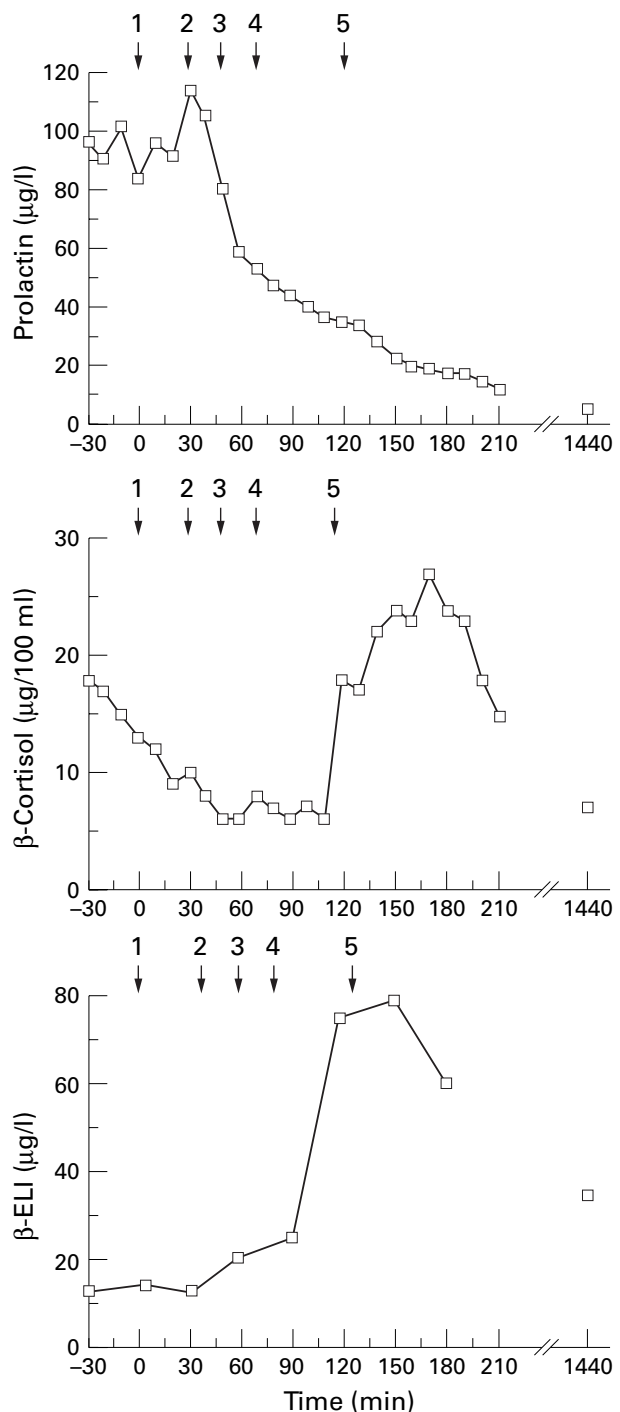

described. ${ }^{15-17}$ The limit of detection and the intra-assay coefficient of variation were 2 $\mathrm{pg} / \mathrm{ml}$ and $7 \%$ for ACTH, and $3 \mathrm{pg} / \mathrm{ml}$ and $9 \%$ for $\beta$-endorphin. The cross reactions for $\beta$-endorphin were $50 \%$ with $\beta$-lipotropin, $<1 \%$ with leu-enkephalin and met-enkephalin, and $<0.5 \%$ with dynorphin 1-17. Other opioid peptides did not interfere with the assay.

\section{STATISTICAL ANALYSIS}

The Mann-Whitney $U$ test was used to compare basal hormone concentrations in patients and controls, analysis of variance (ANOVA) to compare intraoperative changes in hormone concentrations, and Spearman's rank coefficient to analyse the correlation between $\beta$-endorphin, ACTH, and cortisol concentrations. Spearman's correlation coefficient was calculated on the means of $\beta$-endorphin, cortisol, and ACTH concentrations .
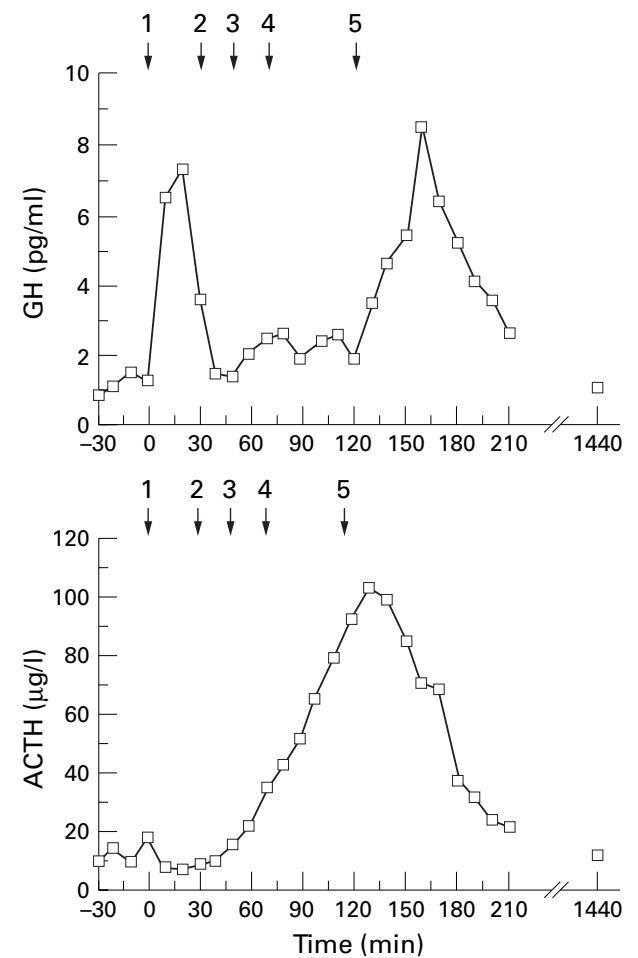

Figure 3 Preoperative, perioperative, and postoperative changes in the concentrations of cortisol, ACTH, $\beta$-endorphin, $G H$, and prolactin in a case of microprolactinoma surgery. In this patient, for technical reasons, the cutaneous incision was made 30 minutes (not 10 minutes) after induction, by contrast with the other patients. Note that there is an early peak of $G H$ before the surgical procedure. 

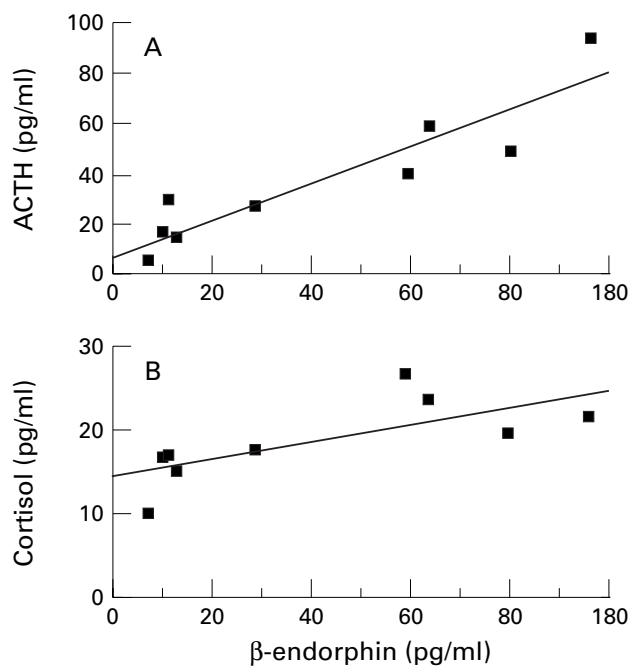

Figure 4 Regression curve of $\beta$-endorphin versus $A C T H$ and cortisol concentrations in 32 patients operated on for microprolactinoma. The curve was plotted after taking into account mean plasma concentrations of ACTH, cortisol, and $\beta$-endorphin, measured at nine time points: 30 minutes before induction, at the time of induction, then every 30 minutes up to 180 minutes after anaesthesia induction. The last sample was taken 24 hours after extubation.

\section{Results}

Among the 36 patients included in the study, 32 were without recurrence at 186 months, three were not cured. In one patient, for technical reasons, the skin incision was made 30 minutes after induction.

BASAL CONCENTRATIONS

There was no difference in the basal concentrations of $\mathrm{GH}, \mathrm{ACTH}, \beta$-endorphin, and cortisol between patients and controls (table). In patients, the basal concentrations of prolactin were significantly higher (Mann-Whitney, $\mathrm{p}<0.0001)$.

\section{KINETICS}

For all patients, no increase in prolactin concentrations occurred after giving the two treatments with morphine-like drugs (between time 1 and 2 and at time 3, figs 1,2, and 3).

In the 32 potentially cured women (fig 1), there was a dramatic decrease in prolactin concentration which was significant as far as 10 minutes after the end of the resection (time $4+10$ minutes; $\mathrm{p}<0.001$ ).

\section{Growth hormone}

There was a significant increase in GH concentration that started 10 minutes after the moment of anaesthesia induction (time 2; $\mathrm{p}>0.01$ ), becoming maximal 30 minutes after induction (fig 1). There was a second and significant increase in $\mathrm{GH}$ concentration starting at extubation (time $5 ; \mathrm{p}<0.01$ ), becoming maximal 1 hour after incubation.

\section{B-Endorphin}

There was a significant decrease in $\beta$-endorphin, 30 minutes after induction (time $3 ; \mathrm{p}<0.01$ ). Inversely, an increase became significant 60 minutes after induction $(\mathrm{p}<0.001)$, culminating 15 minutes after extubation (fig 1). Plasma concentrations returned to basal 24 hours after extubation.
Cortisol

Cortisol was significantly lower than basal 20 minutes after the induction (time $1+20$ minutes, $\mathrm{p}<0,01)$, and the decrease continued until the end of resection. Inversely, there was a significant high cortisol concentration, $30 \mathrm{~min}-$ utes after the end of the resection (at time $4+30$ minutes; $\mathrm{p}<0.01$ ), culminating 1 hour after extubation and reaching about 1.5 times the basal level. Cortisol returned to basal concentrations 24 hours after extubation.

\section{ACTH}

There was a significant low ACTH plasma concentration, 20 and 30 minutes after induction time $(\mathrm{p}<0.01)$. Inversely there was a significant increase in plasma ACTH concentration 20 minutes after the end of the resection $(\mathrm{p}<0.001)$ with a peak at extubation time (time 5 ).

In the three women in whom the operation was not successful no fall in prolactin concentration was found until time $4+40$ minutes (fig 2). Except for prolactin, hormonal reponses to stress were in the same range as the 32 potentially cured patients.

Finally, in the case of the patient whose operation was delayed, the same hormonal response to surgical stress was obtained (fig 3 ).

\section{Correlations}

There were two $\beta$-endorphin correlations, one with ACTH (Spearman's R=0.95, p<0.001), the other with cortisol (Spearman's $\mathrm{R}=0.88$, $\mathrm{p}<0.001$, fig 4). Cortisol and ACTH were also correlated $(\mathrm{R}=0.87 ; \mathrm{p}<0.0001)$.

\section{Discussion}

Prolactin secretion is under dual control-by inhibiting factors, the most important of which is dopamine ${ }^{18-20}$ - and by stimulatory factors. Among the second, it is established that morphine-like compounds ${ }^{14}{ }^{21}$ such as endogenous opioids, ${ }^{18} 22$ in particular $\beta$-endorphin, ${ }^{13}$ stimulate not only prolactin secretion, but also that of $\mathrm{GH} .{ }^{23}$ Nevertheless, $\beta$-endorphin in vitro has no direct effect on prolactin secretion, but antagonises the inhibitory control exerted by dopamine. ${ }^{22}$ This inhibitory effect on dopaminergic neurons ${ }^{24} 25$ is thought to be exerted via the activation of $\mu$ and $\mathrm{k}$ receptors. ${ }^{26}$

Plasma $\beta$-endorphin is secreted by the pituitary stem, whereas the $\beta$-endorphin of the CSF arises from the CNS. ${ }^{27}$ In our study, we have measured the plasma concentration of $\beta$-endorphin only every 30 minutes because its half life is longer than the other anterior pituitary hormones. ${ }^{27}$ At the beginning of the operation, $\beta$-endorphin concentrations remained low, undoubtedly because of the administration of exogenous morphine-like drugs that inhibited its secretion from the pituitary. ${ }^{928}$ On the other hand, there was an increase in ACTH and $\beta$-endorphin concentrations, significant $30 \mathrm{~min}$ utes after the transpalatine retractors were installed and continuing in the recovery period. This suggests that either the intensity of pain was sufficient to overcome the negative effect of morphine on CRF secretion or that corticotrophin cells were stimulated by a releasing factor different from CRF. It is known that arginin 
vasopressin (AVP) stimulates $\beta$-endorphin and ACTH secretion. Interestingly, is has been shown that in sheep hypophysial portal blood, a moderate stress induces an equal release of CRF and AVP whereas during an intense stress, AVP secretion was much more stimulated than that of $\mathrm{CRF}^{29}$ As the plasma concentration of $\beta$-endorphin increased about 30 minutes after a painful stimulus ${ }^{30}{ }^{31}$ the pain caused by placing the retractor, despite the concomitant administration of alfentanil, as well as pain stress accompanying awakening, could explain the kinetics obtained in our study. Comparable kinetic results have been published for heart surgery ${ }^{9}$ and pituitary surgery. ${ }^{12}$

The perioperative increases in prolactin and $\mathrm{GH}$ in response to stress have been known for a long time. ${ }^{7}$ In the case of the existence of a prolactin adenoma, however, the administration of opiates does not cause release of prolactin, as reported in the case of non-adenoma cells. ${ }^{14}$ In addition, the dramatic decrease in prolactin concentrations during the operation had apparently no effect on the kinetics of other hormones involved in stress. Indeed the same type of curves were obtained in the three women in whom the operation was not successful, as shown by the absence of a rapid fall in plasma prolactin concentrations .

Concerning GH, the first peak was considered to be due to induction of anaesthesia, which generates intense stress, ${ }^{12}$ and not by pain for the following reasons: (1) in the general case, $\mathrm{GH}$ concentrations increased twofold before any surgical procedure; (2) in the case of the patient whose operation was delayed after induction, there was a GH peak before surgery, the amplitude of which was comparable with that seen in the other patients. These findings suggest that the first GH peak was related to induction stress alone. The second GH peak occurred at the same time as consciousness was regained, about 40 minutes after the $\beta$-endorphin peak. As it is impossible to dissociate pain from the stress of awakening at that time, it is not possible to determine if the second peak was caused by pain, by stress, or by both at the same time. Because ACTH and $\beta$-endorphin are cosecreted, the differential timing of secretion in $\mathrm{GH}$ and $\beta$-endorphin is also found between GH and ACTH. This is seen not only during surgical stress but also during dynamic tests of pituitary function. Thus it is not possible to conclude that the underlying stress is different for the two groups of hormones. However, as GH secretion is not modified by exogenous opioids during anaesthesia, measurement of $\mathrm{GH}$ may be a useful marker of stress during surgery for microprolactinoma.

The response of the adrenal cortex to surgical stress is attenuated by the administration of morphine-like drugs, ${ }^{89}$ perhaps via the inhibition of release of $\mathrm{CRF}^{32} 33$ and of ACTH. ${ }^{34}$ By contrast, morphine antagonists stimulate ACTH secretion in animals ${ }^{35}{ }^{36}$ and in humans ${ }^{37}$ suggesting the existence of an inhibitory tonic control exerted by endogenous opioids on the anterior pituitary. ${ }^{32} 3738$ These effects could be secondary to central or peripheral mechanisms, but also to a direct action of opioids on endocrine glands. ${ }^{39}$ The increase in circulating cortisol concentrations at the time of awakening in the present study, although moderate, was significant and confirms prior findings. ${ }^{1140}$ This postoperative increase may be attributed to the disinhibition of the corticotrophic axis during drug withdrawal. However, the increase in cortisol during surgical stress is probably an epiphenomenon because the increase is too small to have strong biological effects. ${ }^{41}$ It was not possible to include an adequate control group in this study. As we have not included a surgical control group, the responses measured may or may not be specific for pituitary surgery or for the patients with hyperprolactinaemia, but this was not the aim of our study.

Hormonal responses to surgical stress have been studied in both general anaesthesia ${ }^{14}$ and epidural or peridural anaesthesia. ${ }^{10}{ }^{42}$ The recent appearance of endoscopical surgical techniques had raised hopes for reduced surgical stress in comparison with conventional surgery, but this hope has been dashed by the comparative study of the main markers of stress during different types of anaesthesia. ${ }^{42}{ }^{43}$

Finally, the existence of a correlation between $\beta$-endorphin and ACTH concentrations has been known for almost 20 years. ${ }^{44}$ This correlation is apparently unchanged by the presence of a prolactin tumour.

Our conclusions are summarised thus:

(1) During prolactinoma surgery, the existence of an early $\mathrm{GH}$ peak at the anaesthesia induction time, independently of any surgical procedure, strongly suggests that $\mathrm{GH}$ is a preferential marker of surgical stress, whereas $\beta$-endorphin is secreted in response to pain.

The fact that $\mathrm{GH}$ is a marker of surgical stress has been established in many surgical states including pelvic surgery. ${ }^{45}$ Our results strongly suggest that this is also true during surgery for microprolactinoma. As it was reported in children that the increase in stress hormone concentrations during surgical procedures is associated with postoperative metabolic complications, ${ }^{8}$ it will be interesting to study the relation between high GH concentrations and postoperative complications.

(2) The rapid fall in prolactin concentrations has no effect on the release of other hormones involved in stress.

(3) The administration of opiates does not cause the release of prolactin, as previously was reported in vitro, from non-adenoma cells.

1 Sandberg AA, Eik-Nes K, Samuels LT, et al. The effects of surgery on the blood levels and metabolism of 17hydroxycorticosteroids in man. F Clin Invest 1954:33;1509.

2 Hume DM, Bell CC, Bartter F. Direct measurement of adrenal secretion during operative trauma and convalescence. Surgery 1962:52;74.

3 Gann DS, Egdahl RH. Responses of adrenal: corticosteroid secretion to hypotension and hypovolemia. 7 Clin Invest 1965:44:1.

4 Dubois M, Pickard D, Cohen M. Plasma $\beta$-endorphin immunoreactivity is raised by surgical stress, but not anaesthetic induction [abstract]. Anesthesiology 1982:55; A244.

5 Moore FD, Steenburg SW, Ball MR, et al. Studies in surgical endocrinology. I The urinary excretion of 17hydroxycorticoids, and associated metabolic changes, in cases of soft tissue trauma of varying severity and in bone cases of soft tissue trauma of varying
trauma. Ann Surg 1995:141;145. 
6 Cooper CE, Nelson DH. ACTH levels in preoperative and surgically stressed patients. F Clin Invest 1962:41;1599.

Gordon IN, Suh HK, Stone JG, et al. Human prolactin and growth hormone release during surgery and other conditions of stress. 7 Clin Endocrinol

8 Anand KJS, Sippell WG, Aynsley-Green A. Randomised trial of fentanyl anaesthesia in preterm babies undergoing surgery: effects on the stress response. Lancet 1987:31;2438.

9 Anand KJS, Phil D, Hickey PR. Halothane-morphine compared with high dose sulfentanyl for anesthesia and postop-
erative analgesia in neonatal cardiac surgery. $N$ Engl f Med 1992:1;1-9

10 Giaufre E, Conte-Devolx B, Morisson-Lacombe G, et al. Anesthesie peridurale par voie caudale chez l'enfant: étude des variations endocriniennes. Press Med 1985:14;201-3.

11 Udelsman R, Norton JA, Jelenich SE, et al. Responses of the hypothalamic-pituitary-adrenal and renin-angiotensin axes and the sympathetic system during controlled surgical and and the sympathetic system during controlled surgical and

12 Spaziante R, Merola B, Colao A, et al. $\beta$-Endorphin concentrations both in plasma and in CSF in response to acute trations both in plasma and in CSF in resp

13 Ragavan VV, Frantz AG. Opioid regulation of prolactin secretion: evidence for a specific role of b-endorphin. Endocrinology 1981:109;1769-71.

14 Priou A, Bruder N, Begou D, et al. Glycosylated and non glycolsylated prolactin forms are increased after opioïd administration as part of surgical anaesthesia. Clin Endocrinol 1995:43;213-7.

15 Chrousos GP, Schulte HM, Pldfield EH, et al. The corticotropin-releasing factor stimulation test: an aid in the evaluation of patients with Cushing's syndrom. $N$ Engl $f$ Med 1984:310;622.

16 Guieu R, Devaux C, Albanese J, et al. $\beta$-Endorphin in multiple trauma victims Can F Neurosci 1995:22;160-3.

17 Guieu R, Tardy-Gervet MF, Giraud P. Met-enkephalin and $\beta$-endorphin are not involved in vibration-induced analge3-endorphin are not in
sia. Pain 1992:48;83-8.

18 Gala RR. The physiology and mechanisms of stress-induced changes in prolactin secretion in the rat Life $\mathrm{Sci}$ changes in prolacti

19 Ben-Jonathan N. Dopamine: a prolactin inhibiting hormone. Endocrinol Rev 1985:6;564-89.

20 Neill JD. Prolactin secretion and its control. In: Knobil E Neill JD, eds. The physiology of reproduction. New York: Raven, 1988:1379-86.

21 Enjalbert A, Rubert M, Fiore L, et al. Effect of morphine on the dopamine inhibition of pituitary prolactine release in vitro. Eur f Pharmacol 1979:53;211-2.

22 Enjalbert A, Rubert M, Arancibia S, et al. Endogenous opiates block dopamine inhibition of prolactin secxertion in vitro. Nature 1979:280;595-7.

23 Rivier C, Vale W, Ling N, et al. Stimulation in vivo of the secretion of prolactin and growth hormone by secretion of prolactin and growth horphin. Endocrinology 1977:100;1232-7.

24 Gudelsky G, Porter JC. Morphine and opioïd peptides induce inhibition of the release of dopamine from tubero induce inhibition of the release of dopamine from

25 Dobson PRM, Brown BL. Involvement of the hypothalamus in opiate-stimulated prolactin secretion. Regul Pept 1988 : in opiate-stim

26 Pfeiffer DG, Pfeiffer A, Almeida OFX, et al. Opiate suppression of LH secretion involves central receptors differen from those mediating opiates effects on prolactin secretion f Endocrinol 1987:114;469-76.
27 Grossman A, Moult PJA, Cunnah D, et al. Different opioï mechanisms are involved in the modulation of ACTH and gonadotropin release in man. Neuroendocrinology 1986:42; $357-60$

28 Dubois M, Pickard D, Cohen M, et al. Effects of fentanyl on the response of $\beta$-endorphin immunoreactivity to surgery. Anesthesiology 1982:57;468-72

29 Caraty A, Grino M, Locatelli A, et al. Insulin-induced hypoglycemia stimulates corticotropin-releasing factor and rinine vasopressin secretion into hypophysial portal ( 1990:85;1716-21.

30 Akil H, Richardson DE, Barchas D, et al. Appearance of endorphin-like immunoreactivity in human ventricular erebrospinal fluid upon analgesic electrical stimulation. Proc Natl Acad Sci USA 1978:75;5170-2.

31 Terenius L, Wahlstrom A. Endorphins and clinical pain, an overview. Life Sci 1980:6;261-76

32 Tsagarakis S, Navara P, Rees LH, et al. Morphine directly modulates the release of stimulated corticotrophinreleasing factor-41 from rat hypothalamus in vitro. Endocrinology 1989:5;2330-5.

33 Hockings GI, Grice JE, Walters MM, et al. A synergistic adrenocorticotropin response to naloxone and vasopressin adrenocorticotropin response to naloxone and vasopressin endogenous CRH. Clin Neuroendocrinol 1995:61;198-206.

34 Stubbs WA, Delitala G, Jones A, et al. Hormonal and metabolic responses to an enkephalin analogue in normal man. Lancet 1970:ii;1225.

35 Irvine CHG, Alexander SL, Turner JE. Differential effects of graded doses of naloxone on the reproductive and adrenal axes in seasonally anestrous mares. Endocrinology 1994 . 2;913-9.

36 Alexander SL, Irvine CHG. The effect of naloxone administration on the secretion of CRH, arginine vasopressin, and adrenocorticotropin in unperturbed horses Endocrinology 1995:11;5139-47.

37 Volavka J, Cho D, Mallya A, et al. Naloxone increases ACTH and cortisol levels in man. N Engl F Med 1979:300; 1056-7.

38 Grossman A, Rees LH. The neuroendocrinology of opioïd peptides. Br Med Bull 1983:39;83-8.

39 Carr DB, Ballantyne JC, Osgood PF, et al. Pituitary adrenal stress response in the absence of brain pituitary connection. Anesth Analg 1989:69;197-201.

40 Rem J, Brandt M. Prevention of post-operative lymphopenia and granulocytosis by epidural analgesia. Lancet 1980:i; and grant $283-5$.

41 Udelsman R, Ramp J, Galluci WT, et al. Adaptation during surgical stress. A re-evaluation of the role of glucocorticoids. F Clin Invest 1986:77;1377-81.

42 Schulze S, Roikjaer O, Hasselstrom L. Epidural bupivacaine and morphine plus systemic indomethacin eliminates pain but not systemic response and convalescence after cholecystectomy. Surgery 1988:103;321-7.

43 Deuss U, Dietrich J, Kaulen D, et al. The stress response to laparoscopic cholecystectomy: investigation of endocrine parameters. Endoscopy 1994:26;235-8.

44 Guillemin R, Vargo T, Rossier J, et al. $\beta$-Endorphin and adrenocorticotropin are secreted concomitantly by the adrenocorticotropin are secreted concom
pituitary gland. Science 1977:197;1367-9.

45 Lyons FM, Bew S, Sheeran P, et al. Effects of clonidine on the pituitary hormonal response to pelvic surgery. $\operatorname{Br} \mathcal{F}$ Anaesth 1997:2;134-7. 